\title{
Analysis of Citizenship for AI (Artificial Intelligence)
}

\author{
Heng $\mathrm{Gao}^{1, *}$
}

\author{
${ }^{1}$ Law School, Beijing Institute of Technology, Beijing 100081, China \\ *Corresponding author. Email: 874633613@qq,com
}

\begin{abstract}
Multiple people are aware of the importance of giving citizenship to artificial intelligence. Taking Dubai's grant of citizenship to the intelligent robot Sophia as an opportunity, this article analyzes the relationship between artificial intelligence and citizenship, the definition of citizen and citizenship, and the definition of artificial intelligence, and introduces what kind of citizenship can be obtained by artificial intelligence. Besides, this paper analyzes the necessity of artificial intelligence to obtain citizenship based on many scholars and existing cases, deeply analyzes whether artificial intelligence should obtain citizenship. The third part of this paper is about the acquisition of citizenship by artificial intelligence and which citizenship rights can be obtained on the basis of citizenship. Given the current level and speed of technological development, it is imperative for artificial intelligence to obtain citizenship rights. Simply discussing whether or not to grant them citizenship can't solve the problems encountered by artificial intelligence in the development of rights. According to different levels of technological development, different degrees and types of citizenship should be given to them. This is the top priority in solving the problem.
\end{abstract}

Keywords: Citizenship, Rights, Artificial intelligence.

\section{INTRODUCTION}

Artificial intelligence plays an important role in the current social development process, and because of its intelligent development, people have more expectations for AI. In 2016, Hansen Robotics developed an AI robot called Sophia. Not only does she look like a human, but she can also express emotions through facial expressions and tone changes. It can be said that it is a very successful AI robot at the moment. Because of this, the Dubai government granted Sofia citizenship in 2017, and she became the first robot in history to obtain citizenship. This has also triggered a discussion about whether AI can have citizenship. Hansen, as the developer of this machine, also confidently stated that in some future era, humans and robots will be indistinguishable, and AI will evolve to a critical point and then become a friend of mankind. The word "indistinguishable" is not the appearance of consistency, but it can think independently like humans and have the same other characteristics as humans. This triggered a question that whether AI should have the same rights as humans and whether this is a reason for AI to obtain citizenship. This article will firstly discuss the relationship between artificial intelligence and citizenship, citizen and citizenship, which citizenship rights can be obtained by artificial intelligence, and analyze the pros and cons of artificial intelligence to obtain citizenship rights, finally explore which rights artificial intelligence can obtain. In different era background, whether AI should obtain different degrees of citizenship.

\section{THE CONNECTION BETWEEN AI AND CITIZENSHIP}

\subsection{The Definition of Citizen and Citizenship}

The Oxford Law Dictionary by David Walker defines a citizen as "the legal connection between an individual and a particular country or political community."[1] In this way, citizens are regarded as participants in national affairs. Existing AI can indeed provide certain support for national affairs. For example, intelligent document processing can quickly implement residents' opinions to specific departments, effectively identify the individual needs of citizens and promote refined government governance[2]. Intelligent auxiliary decision- 
making helps the government find solutions to the same problems and then improve its efficiency. However, AI in this case is just a tool, and cannot independently participate in national affairs as a subject. Citizens and citizenship are born together. Marx has a deep understanding of citizens. He divides people into civil society people and burgerliche gesellschaft in a dichotomy. People are in a dual organization. As citizens, they participate in national affairs in state organizations and have public rights; as residents and they can enjoy the rights of life, health, and property freedom[3]. Thinking of Marx's dichotomy can help us understand what citizenship rights can AI obtain.

\subsection{The Definition of Artificial Intelligence}

Is artificial intelligence a smart machine or a robot? According to professor Guangyun Cheng's understanding, if $\mathrm{AI}$ is an intelligent machine, it is just a tool and an extension of human practice. If it is a robot, it exists as a new species or a new human being. These two understandings of AI will have different attitudes towards AI. Tools do not require citizenship and exist as objects just like cars, mobile phones and other tools. But now more scholars treat artificial intelligence as an independent new species, or an individual similar to human beings[4]. A discussion resolution adopted by the European Commission in April 2018 clearly defined artificial intelligence, that is, "Artificial intelligence (AI) refers to a system that analyzes the environment and takes actions (with a certain degree of autonomy) to achieve specific goals. The system can be based only on the software and run in a virtual world (such as voice assistants, image analysis software, search engines, voice and face recognition systems, etc.), or it can be embedded in other hardware devices (such as advanced robots, self-driving cars, etc.)"[5]. This definition describes the nature of artificial intelligence systems with a certain degree of autonomy.

\subsection{Citizenship Right for AI}

The controversy caused by the citizenship that Sofia acquired is the legal right to citizenship itself and Sofia's basic rights that surpass women in the country. Saudi Arabia is a religious country, and the status of women is worrying. According to the Global Gender Gap Report, Saudi Arabia's female status ranks 147 out of 156 countries[6], and the emergence of Sofia as a female citizen is a challenge to Arab women's civil rights. At present, $\mathrm{AI}$ is still in the stage of weak artificial intelligence and does not have the ability to deep learning and thinking. Such AI is more like a product, and giving it all citizenship does not have strong practical meaning. What we should consider the citizenship rights is $\mathrm{AI}$ in the stage of strong artificial intelligence. In response to Marx's thinking about citizenship under Marx's dichotomy, the author agrees with many scholars' point of view that AI can obtain private rights, such as property rights. AI can freely control the property obtained by its labor and ensure that its property is not subject to other external infringements. The law can also protect the right of AI to have glorious titles or other honors due to outstanding contributions or special labor results. The legal protection of the private rights of AI can better promote the development of strong AI as a participant in burgerliche gesellschaft, and it can also regulate people's behavior in the form of law, so that AI can better coexist with humans in harmony.

However, the acquisition of public rights of artificial intelligence still needs to be discussed. AI robots are the unity of tool value and intrinsic value, and the freedom they enjoy is based on their intrinsic value[7]. The intrinsic value of AI robots is to serve humans as a tool, not to be the ruler of humans. AI can provide technical support for the country's major policies and provide suggestions for human decision-making, but it must not be the decision maker. Once given the right to amend laws and formulate national policies, this is a huge challenge to the existence of the existing human world.

\section{ANALYSIS OF THE PROS AND CONS OF ARTIFICIAL INTELLIGENCE ACQUIRING CITIZENSHIP}

At present, only one country has granted its citizenship rights to AI, which has an epic significance for the acquisition of citizenship rights of AI. Scholars from various countries have different attitudes towards this report. Proponents believe that it can help divide the liability for infringement. If the robot itself is responsible, the foundation requires that intelligent robots have personality rights[8]. Personality rights are part of citizenship. Obtaining personality rights can clarify the types of infringement liability. When there is a problem with the product, it is the responsibility of the manufacturer and the producer or the AI that has a legal basis. The manufacturer is responsible for the product quality problems of AI itself. If 
there is a problem in the design or programming of the product itself, the designer should bear the responsibility. Because AI enjoys personality rights and independent property rights, it can compensate the victims. This can help victims to protect their rights that have been violated to the greatest possible extent.

More scholars take the breakthrough of the legal personality system in the current environment as an example and believe that it is reasonable for AI to obtain citizenship. For example, in 2010, Japan established a household registration for the companion robot Palo. In 2014, the New Zealand National Park Te Urewera was approved to obtain the status of a legal person. In 2016, the European Parliament Legal Affairs Committee issued the "Report to the European Commission on Legislative Recommendations on Robot Civil Law Rules". The draft proposes to give the most sophisticated autonomous robot the "cyborg" status and passes it unanimously in 2017[9]. Legal personality is not limited to humans. As a robot that can think alone and is similar to humans, it can gain citizenship.

However, many scholars have also questioned the acquisition of AI citizenship. When humans violate the rights of robots, will humans receive negative legal sanctions[10]? If it is the carrier of AI that is infringed by the crime of deliberately destroying property, or should it be punished by the crime of deliberate injury? Because AI has citizenship, it can think independently, and its sensory ability is almost the same as that of humans. In this way, regulating the behavior of humans and intelligent robots and dividing the boundary is necessary. Additionally, in the era of weak AI, the vast majority of logarithmic AI is manipulated by humans, and humans bear the legal consequences of it. Even if they are granted citizenship, the consequences of their actions are still borne by humans, so it is not practical for them to obtain citizenship.

\section{AI CAN ONLY OBTAIN PARTIAL CITIZENSHIP}

The author believes that AI obtaining part of the citizenship rights may be possible. It can only be obtained within a limited range and cannot threaten the survival, development and dominance of mankind. AI can only obtain citizenship rights and should go through a process, meanwhile, each stage from weak AI to strong AI gives them different rights. The "Esromman 23 Law of Artificial
Intelligence" issued by the Institute of Future Life stipulates the development direction and scope of $\mathrm{AI}$, which has certain reference significance for our understanding of the phased development of AI. Its Article 23 provides for continuous selfimprovement: AI systems that can quickly improve quality or increase quantity through selfimprovement or self-replication must be supplemented by strict safety and control measures[11].

\subsection{Citizenship of AI in the Era of Weak Artificial Intelligence}

The first is the weak AI stage. The current level of technological development is insufficient. At this time, specific regulations are made on the citizenship of AI property, and more should be considered for its algorithms and data sources for specifications and requirements. AI at this time is a tool, and it mostly appears in the form of robots and software, which can be protected by legislation from carrier and algorithmic thinking. As for physical rights, AI has the right to own a complete body, and any violation of its physical integrity has corresponding legal protection. In fact, this not only protects the AI itself, but also makes specific regulations for human behavior.

In addition, regulations on algorithms and data should also be regulated in a timely manner. As early as 2016, Microsoft launched a chat robot Tay, which has a tendency to racial discrimination in just one day[12]. Although the wiring and initial contact weights of the AI neural network are random, the answers to the untrained neural network are also random[13], the basic source of this randomness is the sample data provided by humans, and the sample data itself reflects people's subjective consciousness[14]. AI at this stage is an execution tool. The law should require AI research and development companies to disclose algorithms to the regulatory authorities, and set the scope of data information in the database. Supplemented by corresponding punishment measures, increasing penalties for illegal companies can provide legal environment for the development of AI robots.

\subsection{Citizenship of AI in the Era of Strong Artificial Intelligence}

When it develops into the era of strong AI, the acquisition of citizenship by AI should gradually mature. The enlightenment from Marx's dichotomy of rights, at this time AI in burgerliche gesellschaft 
can already play an indispensable role in society. It can be a teacher, a doctor, a pilot and so on. According to intelligence under different responsibilities, Robots give different codes of conduct, and they enjoy the basic rights in civil society, such as inheritance rights, property rights, health rights, and life rights, etc. This is no different from humans. However, in civil society, they cannot have the right to vote and be elected, and they cannot have the right to political freedom because they are participants in human society rather than the masters. They can serve to liberate the productive forces, but they cannot determine the survival and development of mankind. This is fundamental. In principle, once artificial intelligence takes power, the living environment of human society will be threatened. People must be clear about the purpose of the research and development of AI robots to serve mankind. [15]

\section{CONCLUSION}

Artificial intelligence will bring about tremendous changes in society. Just like the first industrial revolution, it will usher in a new era of human social development, but we should always remember that the purpose of developing $\mathrm{AI}$ is not to replace humans, but to better serve human society. At the same time, the rights of AI should be guaranteed to achieve harmonious coexistence. It is hoped that the discussion on the acquisition of AI citizenship can provide some thoughts. Throughout the world, although Dubai is the first region in the world to grant citizenship rights to AI robots, the United States, Japan, China and other countries have already regarded the development of AI as a national strategic plan. The confrontation between humans and intelligence will continue to promote social development in the future. The boundary between is not something that a certain person or country can achieve, but requires the joint efforts of all mankind.

\section{AUTHORS' CONTRIBUTIONS} Gao.

This paper is independently completed by Heng

\section{REFERENCES}

[1] David M. Walker: "Oxford Dictionary of Law", "Citizen (United States)" entry, published by Guangming Daily Publishing House in 1988, p.161 following
[2] Peng Chen.Government in the era of artificial intelligence: adaptation and transformation[J]. Electronic Government,2019(03):27-34.

[3] Daohui Guo. Citizenship and Civil Society[J]. Law Studies,2006(01):79-88.

[4] Guangyun Cheng. From human-computer relationship to interpersonal inter-subject relationship: the definition and strategy of artificial intelligence[J]. Journal of Dialectics of Nature, 2019,41(01):9-14.

[5] Communication from the Commission to the European Parliament, the European Council, the Council, the European Economic and Social Committee and the Committee of the Regions on Artificial Intelligence for Europe, Brussels, 25.4.2018 COM(2018) 237 final (COM(2018)237final), https://eurlex.europa.eu/legalcontent/DE/TXT/?uri=COM\%3A2018\%3A23 7\%3AFIN ), Last Visit Date: January 19, 2021; Original text: "Artificial intelligence (AI) refers to systems that display intelligent behavior by analyzing their environment and taking actions - with some degree of autonomy - to achieve specific goals. AIbased systems can be purely software-based, acting in the virtual world (e.g. voice assistants, image analysis software, search engines, speech and face recognition systems) or AI

[6] Global Gender Report page10,5,4,2021 https://www.weforum.org/reports?year=2021\# filter

[7] Ziyuan $\mathrm{Wu}$. The identity positioning and right certification of robots in the era of artificial intelligence[J]. Human Rights Research, 2019, 21 (01): 172.

[8] Zichen Ren. Research on the Necessity of Giving Personality Rights to Intelligent Robots[D]. Southwest University, 2019.

[9] Guide Wu.The Intellectual Property Law Protection of German Artificial Intelligence Creations and Its Enlightenment[J]. Electronic Intellectual Property,2021(01):83-97.

[10] Ziyuan $\mathrm{Wu}$. The identity positioning and right certification of robots in the era of artificial intelligence[J]. Human Rights Research, 2019, 21 (01): 172. 
[11] Future of Life Institute,https://futureoflife.org/, Last Visit Date: April 19, 2021.

[12] Why did Microsoft chatbots "learn badly"[N]. Guangming Daily, 2016-04-08(010).

[13] Jian Wang, Yangfan Lu, Yuanpeng Wang, Jiahao Wu, Sailong Zhong. A Brief Talk on Artificial Intelligence - Control Measures in the Era of Artificial Intelligence[J]. Network Security Technology and Application,2021(03):137-139.

[14] Ning Zhang, Caiwei Lv, Chuyi Zhang. News reporting and data bias in the context of big data[J]. Southern Media Research,2018(06):133-142.

[15] John Umbeck, "Might Mikes Right: A Theory of the Formation and Initial Distribution of Property Rights", Economic Inquiry 1981,pp. 38-59. 